\title{
Modeling the 2011 Tohoku-oki Tsunami and its Impacts on Hawaii
}

\author{
Yoshiki Yamazaki ${ }^{1}$, Volker Roeber ${ }^{1}$, Kwok Fai Cheung ${ }^{1}$, and Thorne Lay ${ }^{2}$ \\ ${ }^{1}$ Department of Ocean and Resources Engineering \\ University of Hawai'i at Manoa \\ Honolulu, Hawaii, 96822 USA \\ ${ }^{2}$ Department of Earth and Planetary Sciences \\ University of California Santa Cruz \\ Santa Cruz, California, 95064 USA
}

\begin{abstract}
The 2011 Tohoku-oki great earthquake $\left(M_{w}\right.$ 9.0) generated a destructive tsunami in the near field that devastated the Pacific coast of northeastern Japan. The tsunami, which reached Hawaii 7 hours after the earthquake, caused localized damage and persistent coastal oscillations across the island chain. We use the shock-capturing, dispersive wave model NEOWAVE (Non-hydrostatic Evolution of Ocean WAVEs) to reconstruct the tsunami across the Pacific and its transformation around the Hawaiian Islands. A finite-source model based on inversion of teleseismic $P$ waves provides the detailed rupture processes for modeling of seafloor deformation and tsunami generation. The computed results are validated with surface elevations recorded at GPS and wave gauges along the East Japan coast, DART buoys across North Pacific, and tide gauge and runup measurements at Hawaii. The model results corroborate the impact and damage observed in Hawaii that might be attributed to focusing of energy by seamounts and regional and coastal resonance.
\end{abstract}

Keywords: dispersive wave; Hawaii; inundation; NEOWAVE; runup; The 2011 Tohoku-oki earthquake and tsunami.

\section{INTRODUCTION}

The Tohoku-oki great earthquake (seismic moment magnitude, $M_{W}=9.0$ ) ruptured the megathrust fault offshore of Miyagi and Fukushima in Northeastern Honshu on March 11, 2011, and generated strong shaking across the region and a devastating near-field tsunami with run-up heights reaching in excess of $40 \mathrm{~m}$. The tsunami, which registered $6.0 \mathrm{~m}$ amplitude at a coastal GPS buoy and $1.75 \mathrm{~m}$ at an open-ocean DART buoy, triggered warnings across the Pacific. The waves, which reached Hawaii 7 hours after the earthquake, damaged boats and harbor infrastructure and inundated the west shore of Hawaii Island. The extensive global seismic networks, the dense geodetic instruments, the numerous water level stations, video footage and post-event surveys across the Pacific provide the best quality datasets and coverage of any earthquake and tsunami to date for scientific research and emergency management.
Recent advances in seismic inversion algorithms [1], [2] enable accurate descriptions of dislocation rise time and rupture propagation over the source fault model. These can be used to calculate time series of the seafloor vertical displacement and velocity that constitute the bottom boundary condition for modeling transfer of kinetic and potential energy to the water. It is timely for a paradigm shift in tsunami modeling that parallels the advances in geophysics. NEOWAVE [3], [4] builds on the nonlinear shallow-water equations with a vertical velocity term to account for dispersion in tsunami generation and propagation and a momentum conservation scheme to describe flow discontinuities associated with breaking waves and bores. The vertical velocity term also facilitates modeling of tsunami generation from seafloor deformation to account for the earthquake rupture process. This semi-implicit, finite difference model in the spherical coordinate system uses a twoway grid nesting scheme to describe tsunami generation, basinwide evolution, and coastal inundation in a single computation.

In this paper, we utilize a finite-source rupture model of the 2011 Tohoku-oki earthquake for modeling the tsunami in the near and far-field. The finite-souce model is a slightly updated version of early models $[5,6]$ obtained from least-squares inversion of teleseismic $\mathrm{P}$ waves. It defines the rupture processes and the seafloor deformation for input to NEOWAVE. The finite-source solution is validated by comparing observed and calculated GPS ground motion data across Japan as well as tsunami records at GPS and wave gauges along the Japan coast and DART buoys across the Pacific. Four levels of two-way nested grids capture tsunami evolution processes of different time and spatial scales for investigation of coastal wave impacts around the Hawaiian Islands. Fringing reefs, which are present along $70 \%$ of Hawaii coastlines [7], have been a challenge to various types of coastal wave models. Modeling the tsunami inundation along Hawaii coastlines allows validation of the model capability to predict tsunami impacts in tropical island environments. 

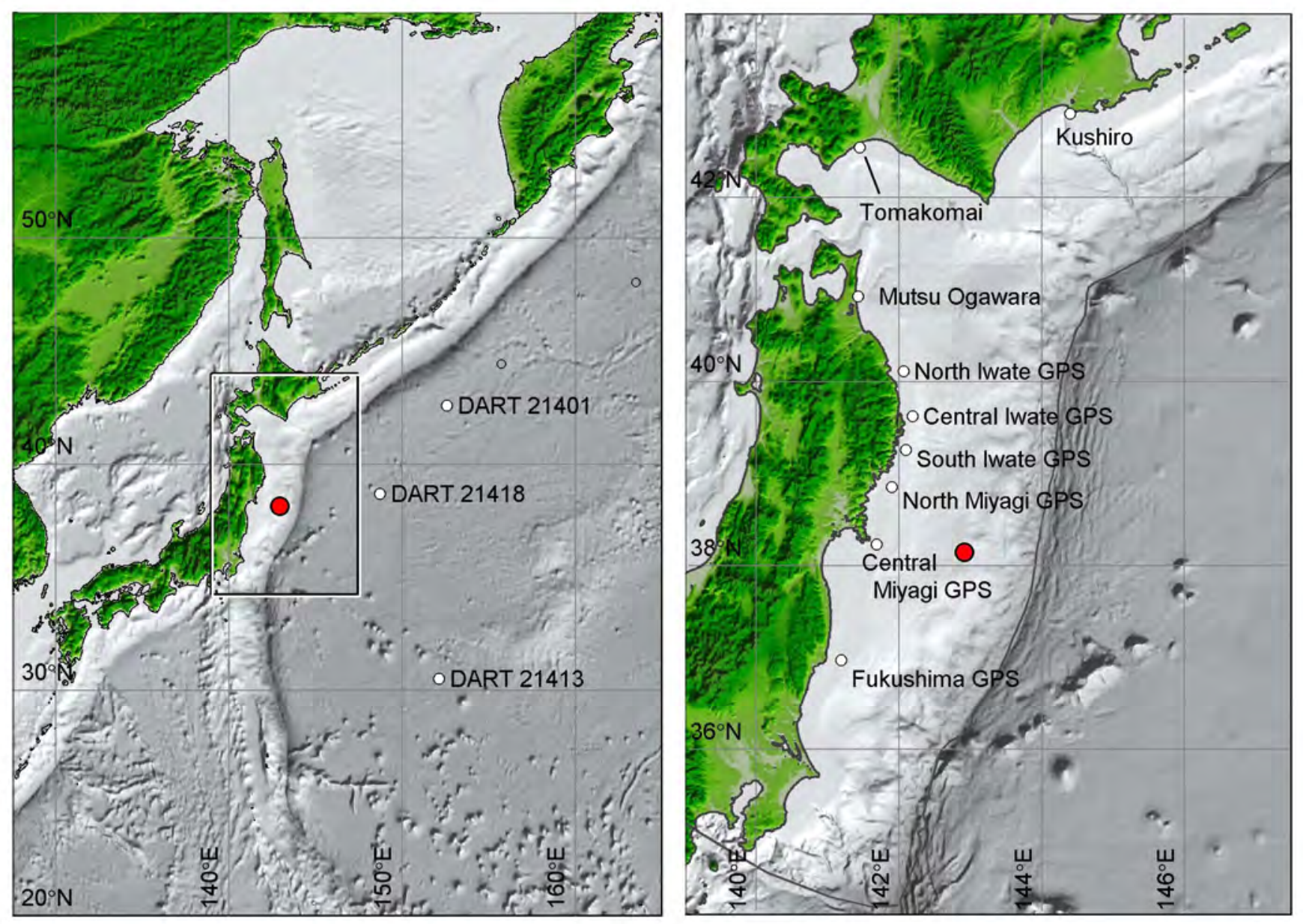

Figure 1. The two levels of nested grid for modeling near-field tsunami; $\circ$ (red), epicenter; $\circ$ (white), water level stations.

\section{TSUNAMI MODEL AND SETUP}

NEOWAVE is a shock-capturing, dispersive wave model in the spherical coordinate system for tsunami generation, basinwide evolution and coastal run-up [3], [4]. The depth-integrated model describes dispersive waves through the non-hydrostatic pressure and vertical velocity, which also account for tsunami generation from time history of seafloor deformation. The semi-implicit, staggered finite difference model captures flow discontinuities associated with bores or hydraulic jumps through the momentum-conserved advection scheme. A twoway grid-nesting scheme utilizes the Dirichlet condition of the non-hydrostatic pressure and both the horizontal velocity and surface elevation at the inter-grid boundary to ensure propagation of dispersive waves and discontinuities across computational grids of different resolution. The capability of NEOWAVE in describing shock-related hydraulic processes was validated at the 2009 Benchmark Challenge of the Inundation Science and Engineering Cooperative Workshop sponsored by the National Science Foundation. The model correctly reproduces the energetic breaking waves and hydraulic processes over a complex reef system in the Tsunami Wave Basin at Oregon State University.

We utilize two systems of nested grids to model the near and far-field tsunami impacts. The two levels of nested grid as shown in Figure 1 model the near-field tsunami. The level-1 grid, which extends across the Northwest Pacific Ocean at 2' resolution, covers the entire Japan-Kurils-Kamchatka trench as well as three DART buoys near Japan. The level-2 grid resolves the continental margin and the rupture and tsunami generation processes in East Japan at 24". The resolution is adequate, but not optimal, to model the tsunamis at the GPS and wave gauges near the coast. Four levels of nested grids are necessary to describe the propagation of the tsunami across the Pacific and inundation at the coastlines in Hawaii. Figure 2a shows the coverage of the level-1 grid across the north Pacific Ocean at 2' resolution. The region includes 16 DART buoys that recorded clear signals of the tsunami. The level-2 and level-3 grids describe tsunami transformation around the Hawaiian Island chain and the individual islands at 15" and 3" resolution, respectively (Figure 2b,c) . The level-4 grid covers the coastal area at 0.3 " resolution to model nearshore wave 


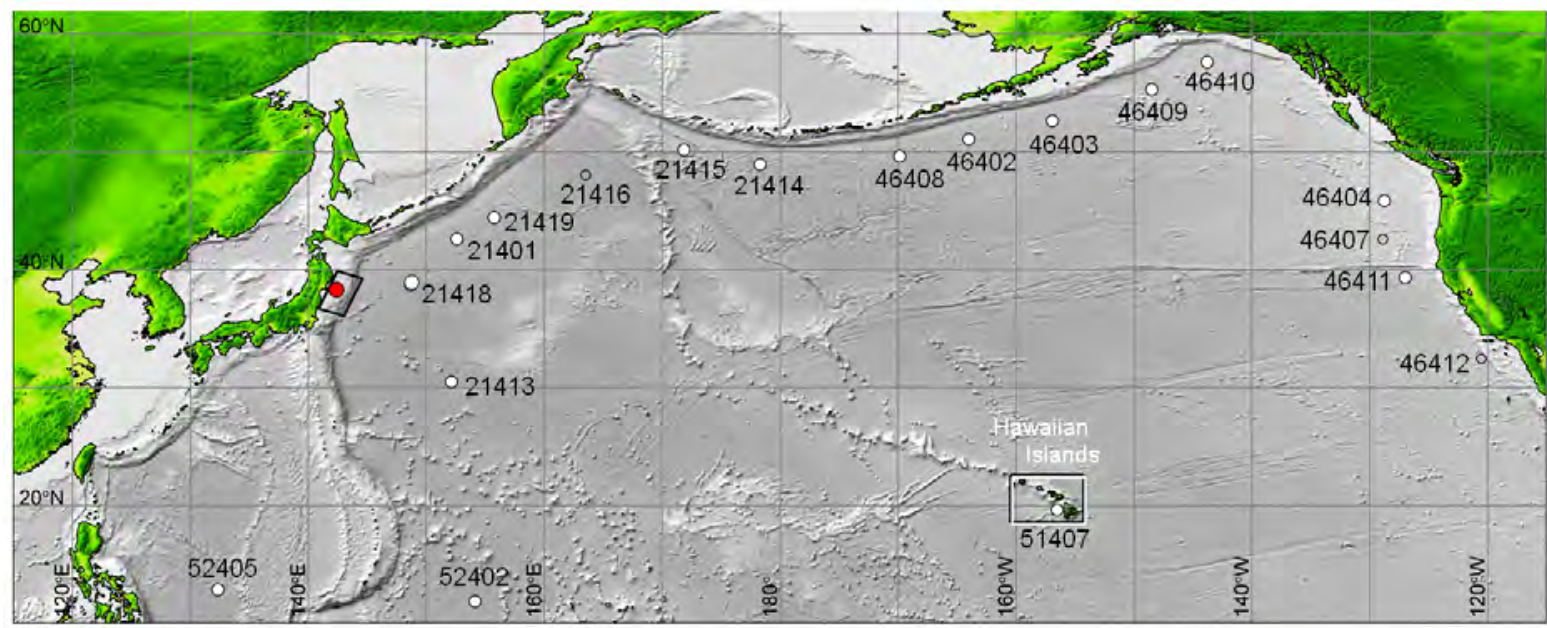

(a)

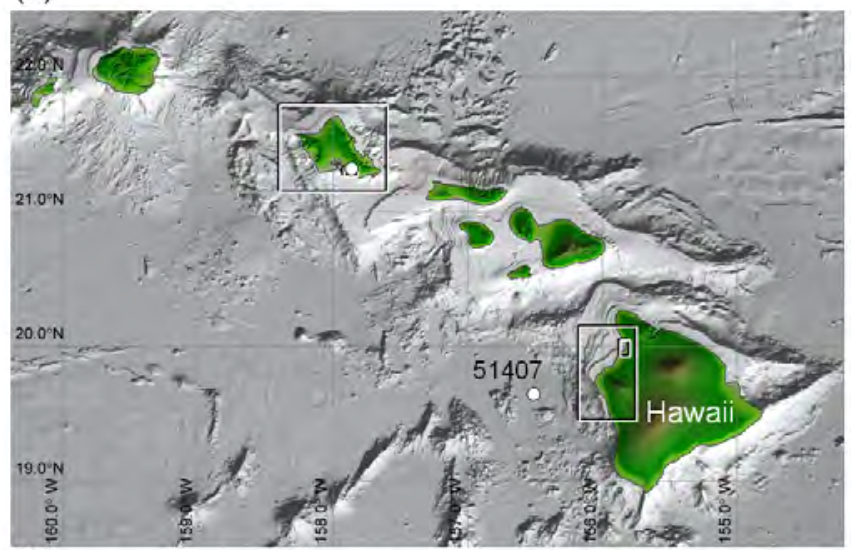

(b)

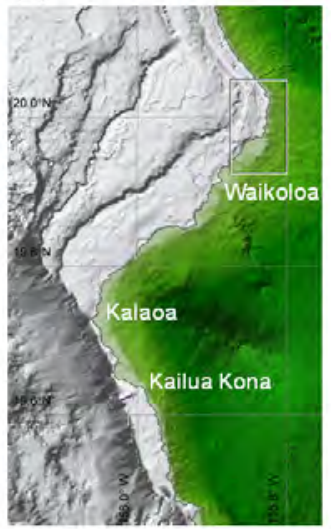

(d)

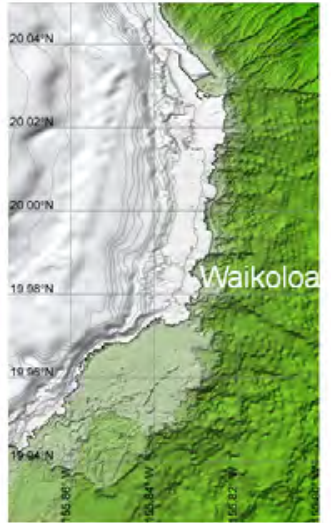

(e)

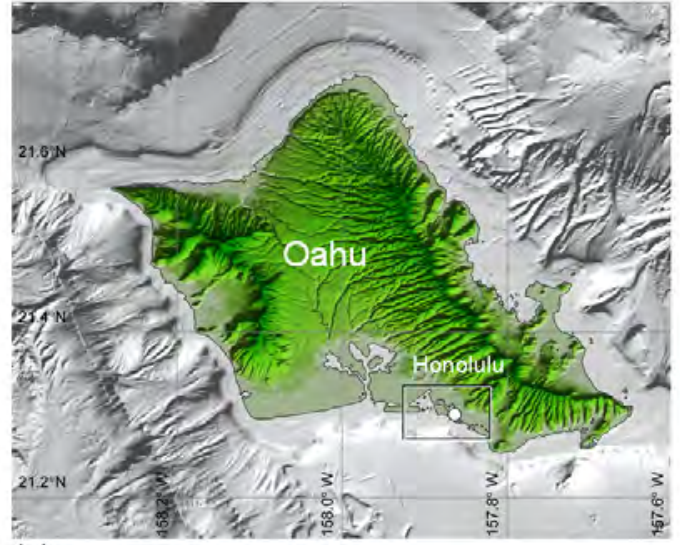

(c)

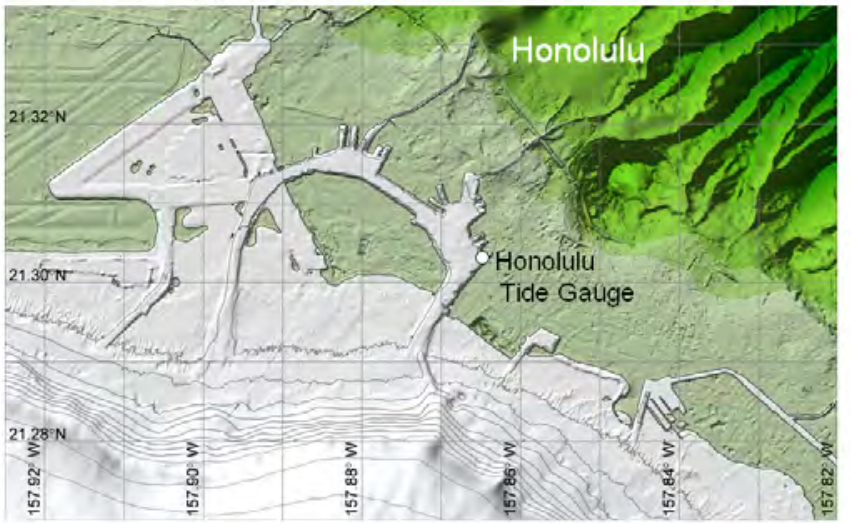

(f)

Figure 2. The four levels of nested grid for modeling tsunami impact on Hawaii; $\circ$ (red), epicenter; $\circ$ (white), water level stations.

transformation and inundation on land (Figure 2d,e,f) . Fringing reefs, which comprise a shallow flat and a steep offshore slope, are evident along the coastlines.

Modeling tsunami observations requires accurate bathymetry over the ocean and high-resolution topography near the coast. We have compiled a digital elevation model with the latest bathymetry and topography in WGS 84 datum and referenced at mean-sea level. The National Geophysical Data Center (NGDC) Global Relief Model ETOPO1 at 1' (1852-m) resolution provides the topography and bathymetry for the North Pacific basin. The Japan Meteorological Agency supplied the bathymetry around Japan at 20" ( $\sim 600-\mathrm{m})$ resolution. A multi-beam survey dataset at 50-m resolution from the University of Hawaii is incorporated into the NGDC Coastal Relief Model of 3" ( $\sim 90-\mathrm{m})$ resolution to define the 


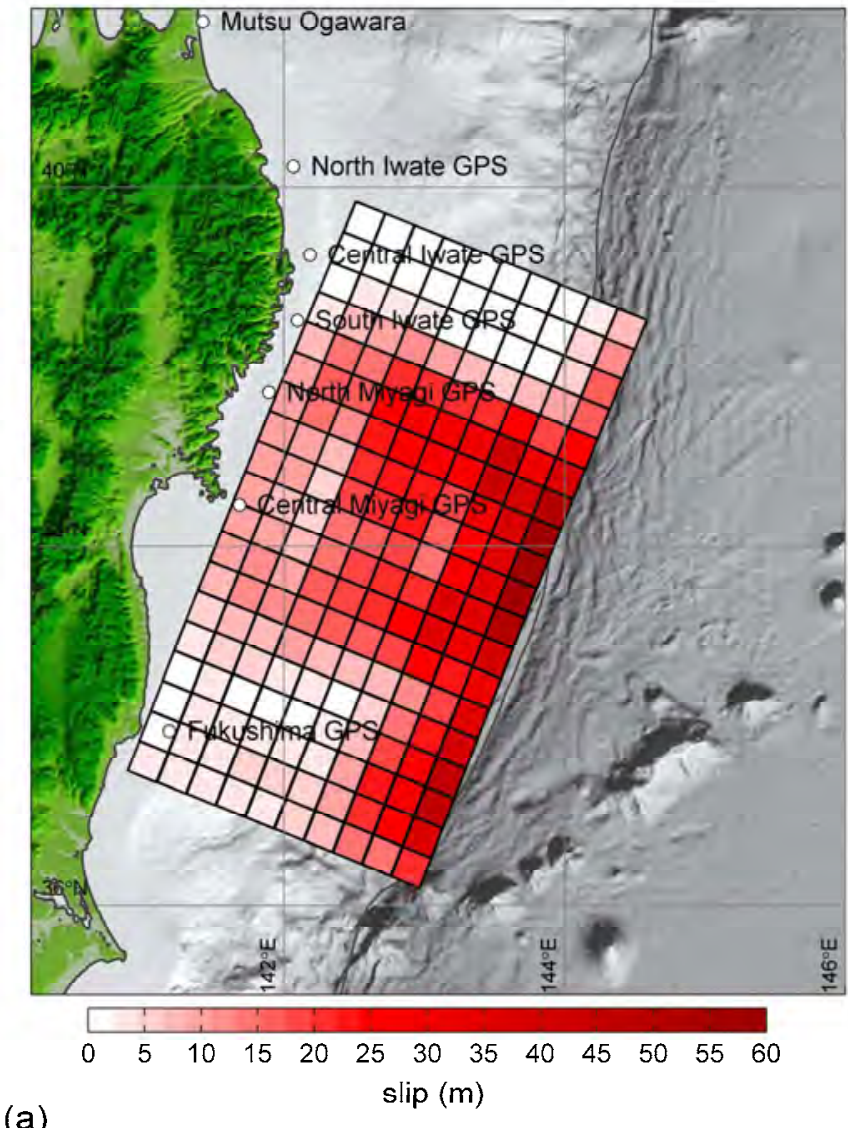

(a)

Figure 3. Slip distribution from the finite source solution. (b) Vertical seafloor displacement; $\circ$ (red), epicenter; $\circ$ (white), water level stations.

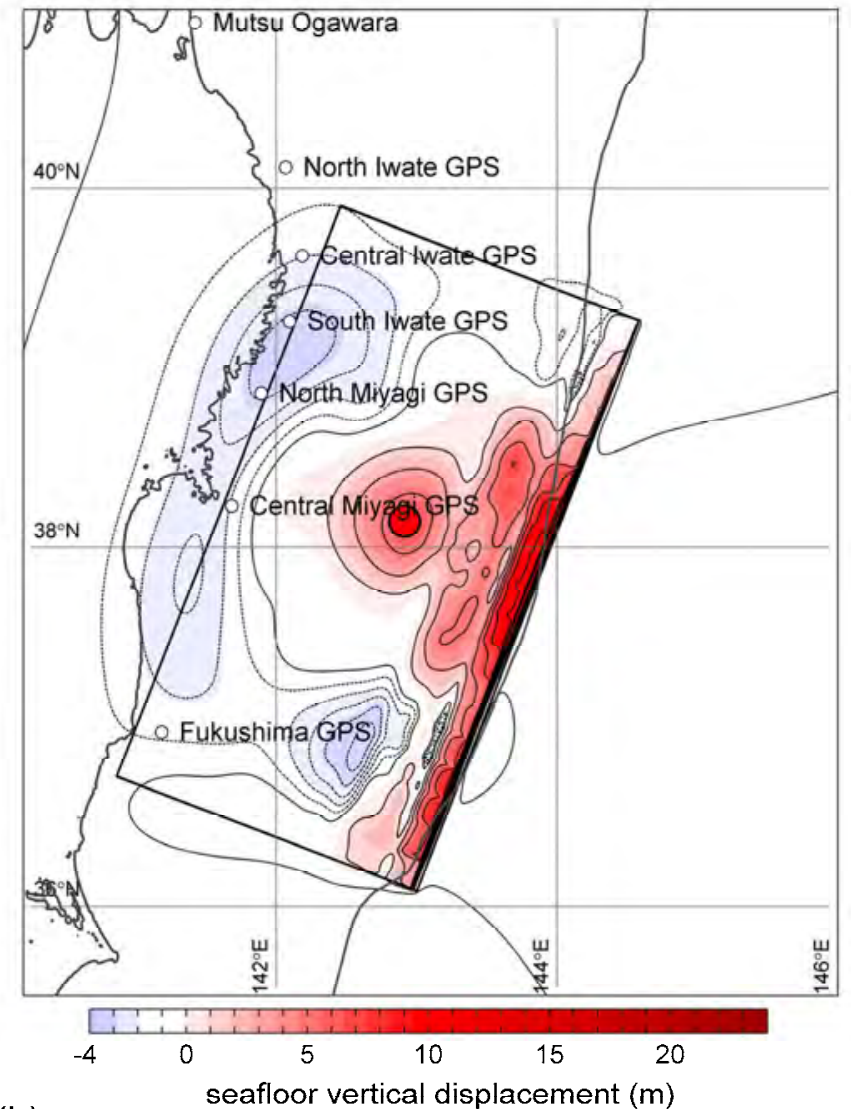

(b) bathymetry and topography in the Hawaii region. LiDAR (Light Detection and Ranging) data of $2 \sim 4 \mathrm{~m}$ resolution is available along Hawaii's coastlines from approximately $40 \mathrm{~m}$ water depth to $15 \mathrm{~m}$ topographic elevation. The data are distributed by the US Army Corps of Engineers and US Geological Survey.

\section{FINITE SOURCE MODEL AND TSUNAMI GENERATION}

The Tohoku-oki earthquake occurred on 11 March 2011 at 05:46:18 UTC. The US Geological Survey (USGS) and the Japan Meteorological Agency (JMA) estimated the moment magnitude $M_{w}$ of 9.0. The estimated location of the hypocenter varies among studies, with a regional three-dimensional seismic velocity model yielding a hypocenter at $38.107^{\circ} \mathrm{N}$ $142.916^{\circ} \mathrm{E}$ with a focal depth of $14.5 \mathrm{~km}$ into the crust [8]. The finite-source model is derived from least-squares inversion of teleseismic $\mathrm{P}$ waves using a layered source-region velocity structure adapted from [2]. The model utilizes a $380 \mathrm{~km}$ long and $200 \mathrm{~km}$ wide fault subdivided into 190 square subfaults of $20 \mathrm{~km} \times 20 \mathrm{~km}$ each. The subfaults have a strike angle of $202^{\circ}$ and a dip angle of $12^{\circ}$. The hypocenter is located at $38.107^{\circ} \mathrm{N}$ $142.916^{\circ} \mathrm{E}$ and $19.5-\mathrm{km}$ depth into the crust. The rupture velocity is $1.5 \mathrm{~km} / \mathrm{s}$ out to $100 \mathrm{~km}$ radius from the hypocenter and $2.5 \mathrm{~km} / \mathrm{s}$ at larger distance.

The finite-source solution estimates the seismic moment as $3.8 \times 10^{22} \mathrm{~N} \cdot \mathrm{m}\left(\mathrm{M}_{\mathrm{w}} 9.0\right)$, compatible with long-period determinations of $\sim 3.9 \times 10^{22} \mathrm{Nm}$ [9]. Figures 3 (a) and (b) show the slip distribution from the finite-source solution and the calculated permanent vertical displacement [10]. The 148-sec duration faulting consists of two primary slip regions, near the hypocenter and along the trench. The individual subfaults have an average rise time of $32 \mathrm{sec}$ and an average slip of $15.0 \mathrm{~m}$ with a maximum value of $58.1 \mathrm{~m}$ near the trench. The seafloor deformation shows two significant uplift regions corresponding to the large fault slip regions and a maximum displacement of $25.2 \mathrm{~m}$ near the trench. The finite-source model defines kinematic seafloor deformation with subfault contributions being computed using the planar fault model of Okada [10]. The deformation is a linear function of the slip and dimensions of the fault. Superposition of the deformation from the subfaults with consideration of their rupture initiation times and rise times reconstructs the time sequence of seafloor vertical displacement and velocity for the input to NEOWAVE [4].

The finite-source solution is validated through comparison of the computed tsunami waveforms and the recorded water-level data surrounding the rupture. The GPS 

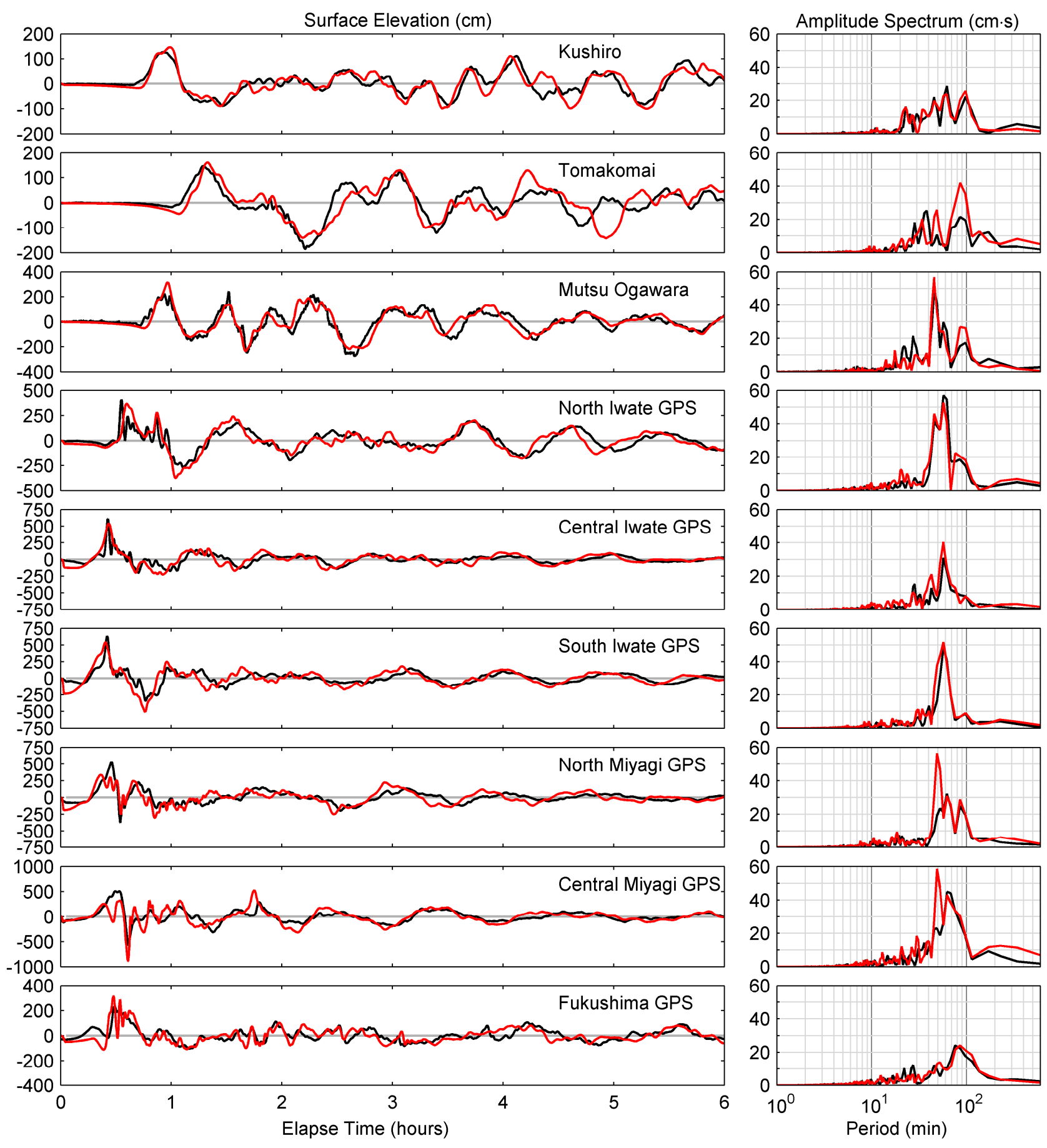

Figure 4. Time series and spectra of surface elevations at water level stations near Japan. ——, recorded data; — $—$, computed data.

and wave gauges, which are located at 120 200-m and 50-m water depth, captured the near-shore tsunami characteristics. Figure 4 shows a comparison of the recorded and computed waveforms and spectra at the gauges. The computed results at the Kushiro, Tomakomai, and Mutsu Ogawara wave gauges north of the rupture area show very good agreement of the arrival time, amplitude, and frequency content with the measurements. The North, Central, and South Iwate, as well as the North Miyagi GPS gauges, which were located immediately west of the major rupture area, recorded around 5 $\mathrm{m}$ wave amplitude. The computed results successfully reproduce these extreme measurements, even though minor 

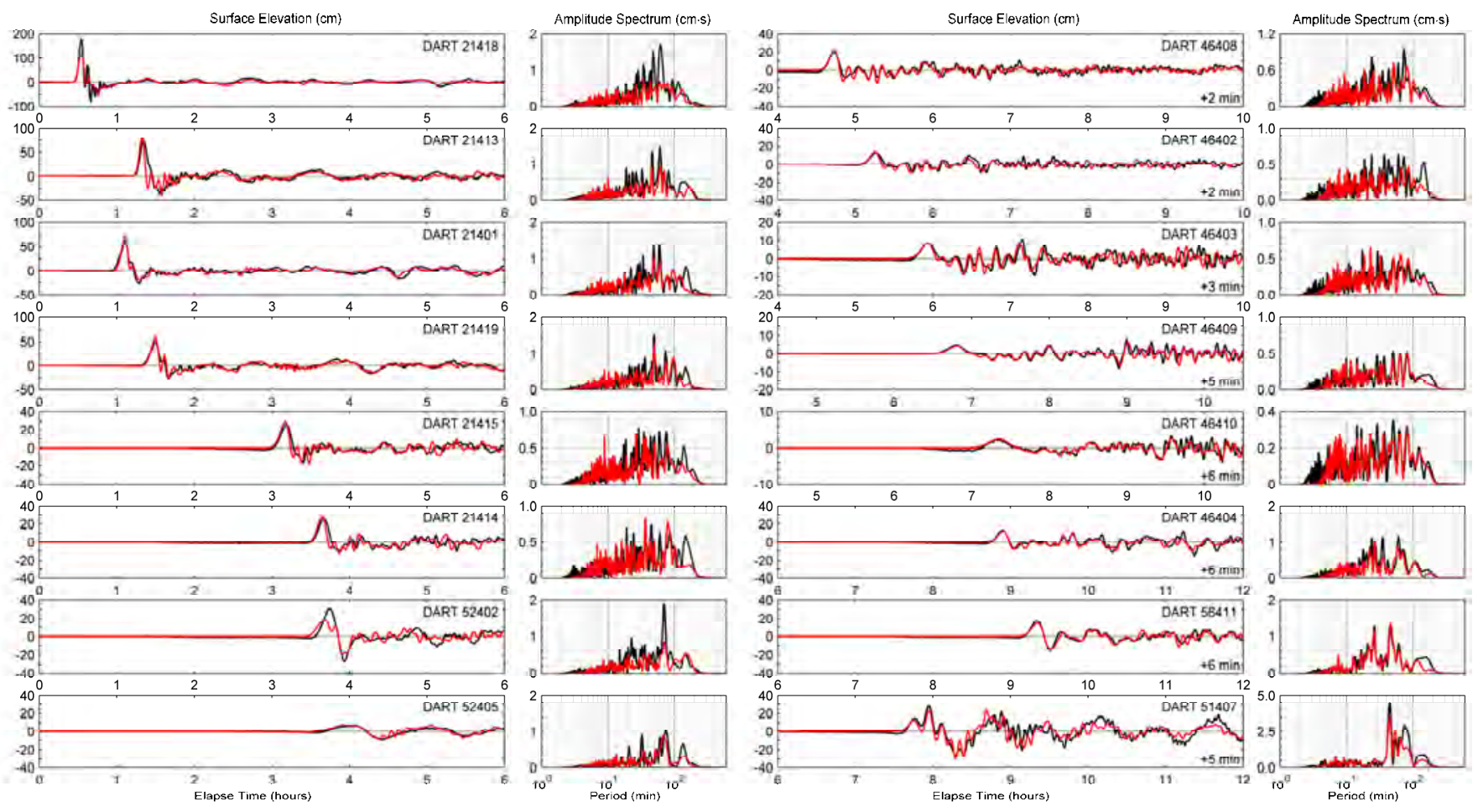

Figure 5. Time series and spectra of surface elevations at DART buoys across north Pacific. $\_$, recorded data; $\_$, computed data.

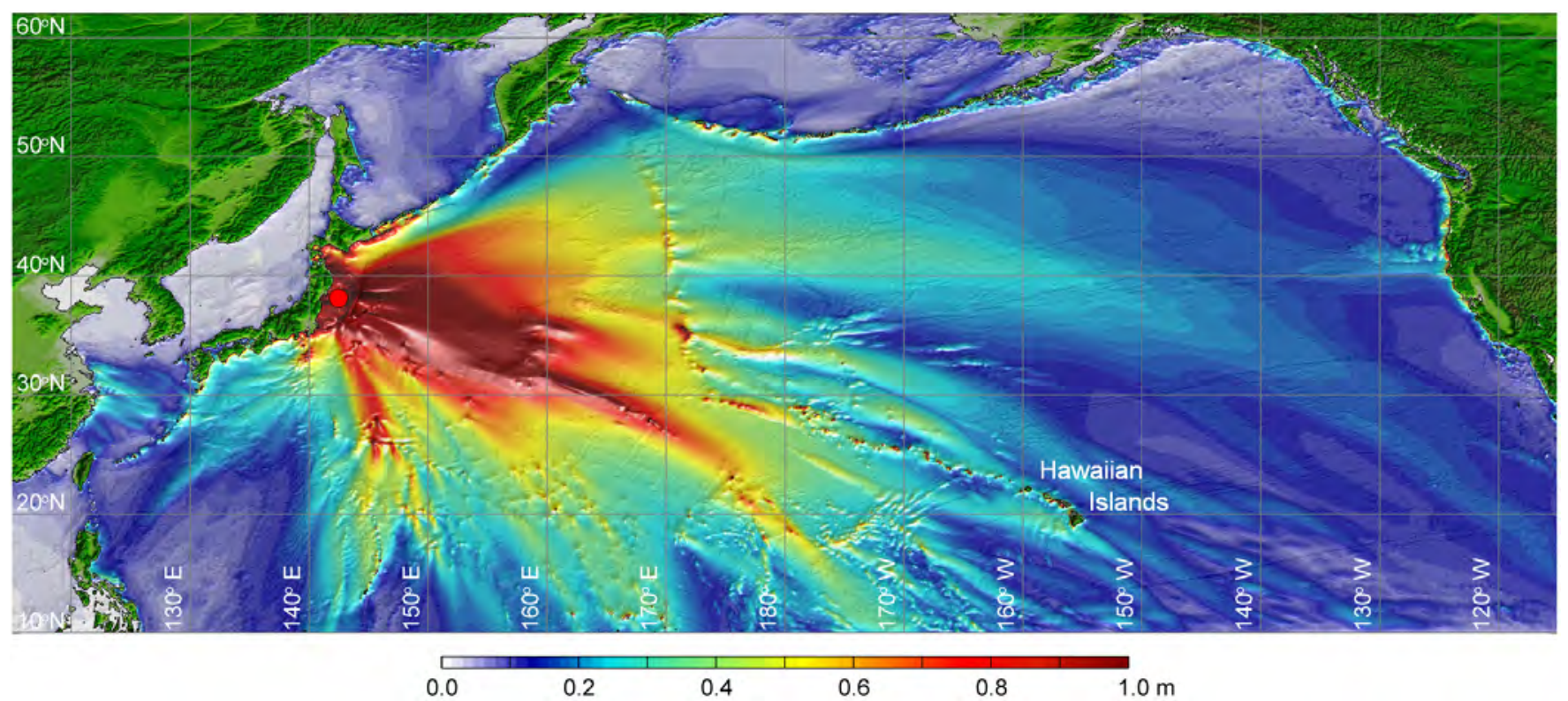

Figure 6. The level-1 grid, computed maximum amplitude across north Pacific.

discrepancies in arrival times and waveforms are observed. The model does not fully capture the initial wave at the North Miyagi, Central Miyagi, and Fukushima GPS gauges, but produces decent agreement at subsequent waves comparable to the gauges to the north and west of the source. The computed results reproduce the dominant processes and show overall good agreement with the measurements, thereby validating the present solution for tsunami generation from seafloor deformation with the finite source model. 


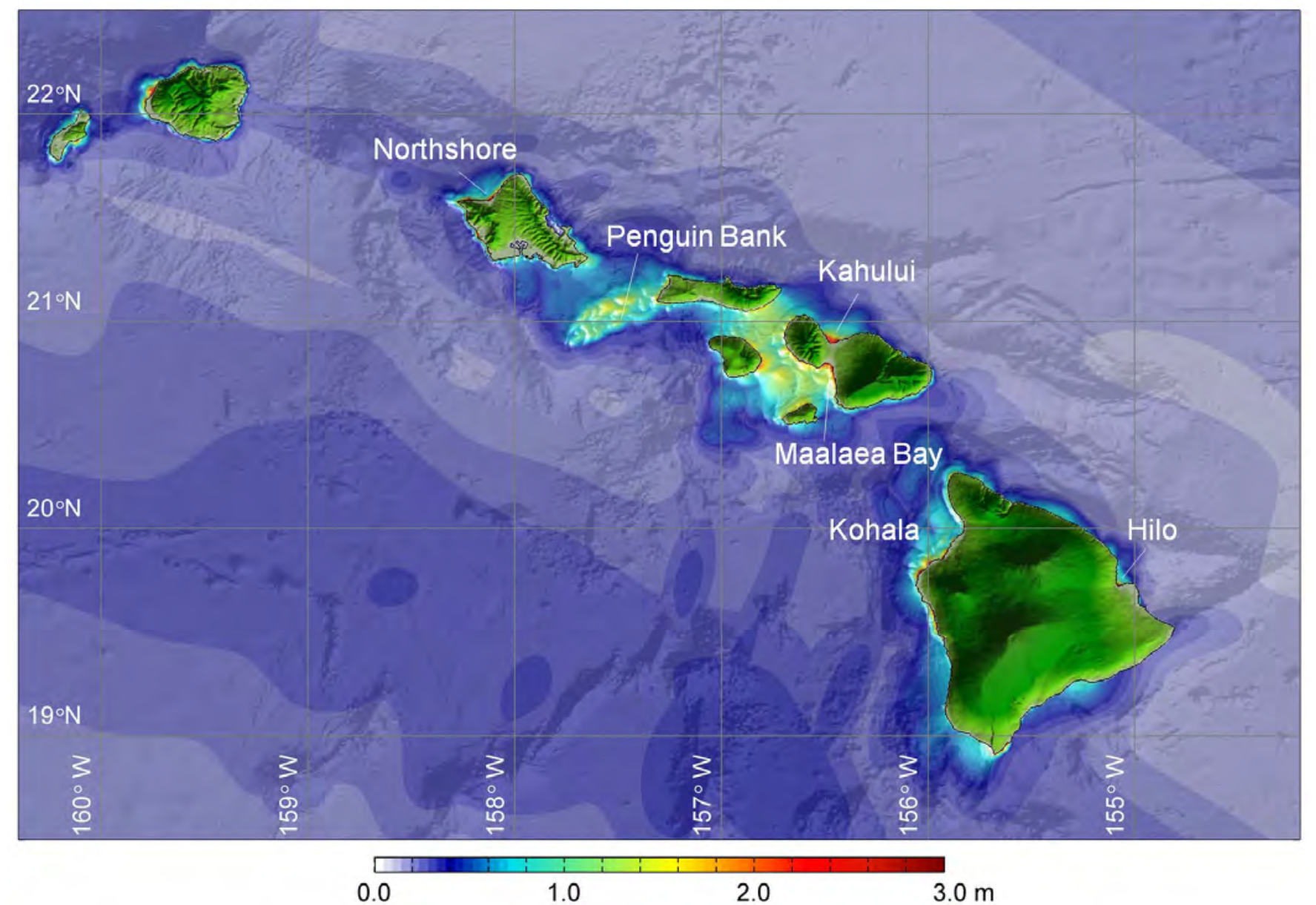

Figure 7. The level-2 grid, computed maximum amplitude over Hawaiian Islands.
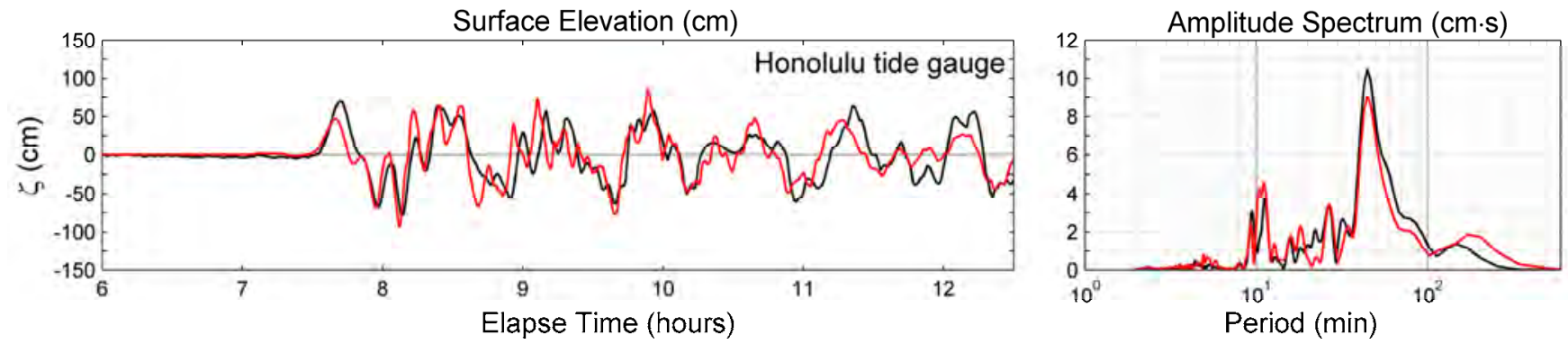

Figure 8. Time series and spectra of surface elevations at Honolulu tide gauge. $\_$, recorded data; $\_$, computed data.

\section{TSUNAMI PROPAGATION AND IMPACT ON HAWAII}

The 2011 Tohoku-oki tsunami is modeled with four levels of nested grids to investigate the impact on Hawaii. Figure 5 compares the surface elevation time series and amplitude spectra at the DART buoys across the north Pacific. The model reproduces the large and distinct initial waves along the Japan coast and to the south. The comparisons near the Aleutian-
Alaska and North America coasts, as well as a location west of Big Island of Hawaii, show very good agreement. The computed waveforms have been shifted by up to $6 \mathrm{~min}$ as indicated in the figure to match the tsunami arrival time. The good agreement of the computed and measured subsequent waves indicates that the model correctly captures the shelf resonance around the Pacific Rim [11]. Figure 6 shows the maximum wave amplitude across the Pacific. The main energy propagates in a direction normal to the Japan trench and passes 


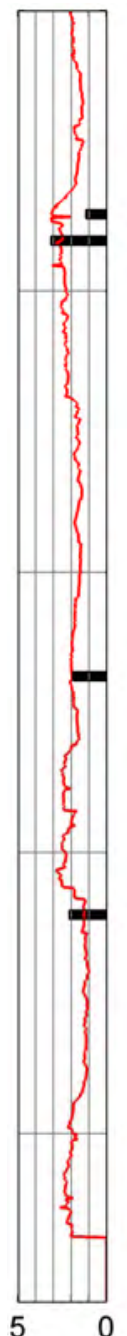

(m)
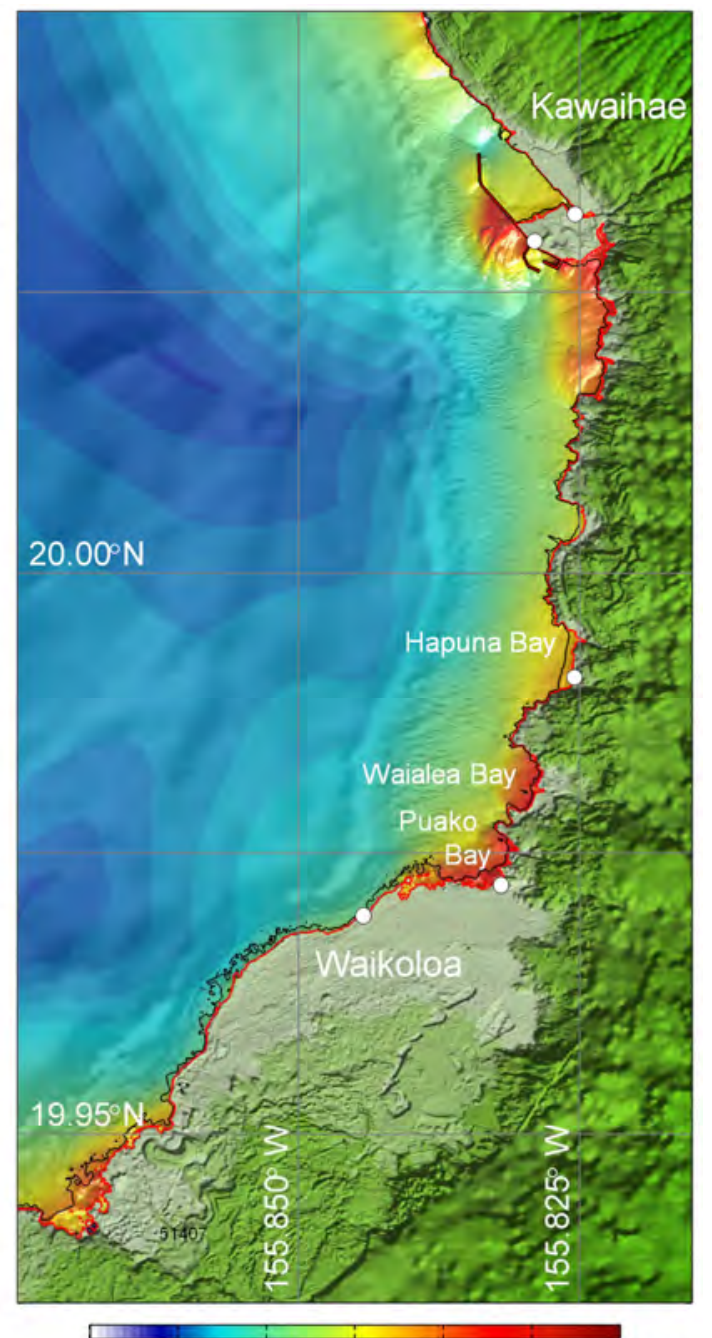
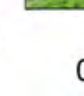

0.0
$3.0 \mathrm{~m}$
Figure 9. Runup, inundation, and maximum amplitude. bar(black): recorded runup;; - , computed data.

south of the Hawaiian Islands. The seamounts along the underwater ridges focus the tsunami waves into high energy beams across the western Pacific, one of which points directly to the west side of Hawaii Island. The waves reach the west coast of North America with considerable amplitude. Refraction at the Mendocino escarpment focuses the wave energy toward Northern California.

The Hawaiian Islands are prone to resonance caused by tsunamis. Figure 7 shows the maximum amplitude around the Hawaiian Islands that corroborates the resonance oscillation modes over the shallow insular shelves including Penguin Bank between Oahu and Molokai [12]. Figure 8 compares the computed and recorded data at the Honolulu tide gauge on the south shore of Oahu. The model slightly underestimates the initial wave, while producing excellent agreement of the phase and frequency content for more than 3 hours. While the south shore of Oahu does not exhibit significant wave amplification, the spectral peak at $42 \mathrm{~min}$ corresponds to regional resonance extending from Oahu to Maui. Nearshore resonance amplification is observed at North Shore of Oahu, Kahului and Maalaea Bays of Maui, and Kohala and Hilo of Hawaii Island similar to [13]. These wave activities, which caused damage to harbor facilities and boats, have been lasting for a couple of days after the tsunami event. Figure 9 shows the computed runup and inundation around Waikoloa, Hawaii Island. A shallow fringing reef, which extends about $1.5 \mathrm{~km}$ offshore, is present in the embayment. The model describes the amplification of the waves across the reef and reproduces the overall pattern and height of the recorded run-up along the coast.

\section{CONCLUSION}

The 2011 Tohoku-oki tsunami and its devastating impacts in Japan and damage across the Pacific provide valuable information for better understanding of tsunami physics and improvement of assessment tools. A wealth of recorded geophysical and hydrographical data from the event and highresolution bathymetry and topography data around the Hawaiian Islands allows reconstruction of the tsunami through numerical modeling and an investigation of the impacts at the affected coastlines.

A seismic wave-derived finite-source model provides the time sequence of rupture processes that drive seafloor deformation for input to NEOWAVE. The model gives excellent agreement with recorded tsunami data along the Japan coasts and across the Pacific. thereby validating the finite-source solution and the capability of NEOWAVE for modeling near and far-field tsunamis. The two-way, grid nesting scheme allows modeling of wave transformation and runup around the Hawaiian Islands. The recorded tide gauge and runup data confirm our capability to predict tsunami impacts in tropical island environments. Further tsunami impact assessments along the coasts of Hawaii with NEOWAVE will provide insights into the effects of fringing reefs on tsunami transformation and runup processes.

\section{ACKNOWLEDGMENT}

This work made use of GMT, and Matlab software. We thank T. Kuwayama for supplying the 20 arcsec Japan bathymetry data. The recorded DART buoy data were obtained from the NOAA National Data Buoy Center. The recorded GPS and wave gauges data were provided by NOWPHAS. The Hawaii Tsunami Observer Program of Hawaii State Civil Defense provided recorded runup data.

\section{REFERENCES}

[1] C. Ji, D.J. Wald, and D.V. Hemberger, "Source description of the 1999 Hector Mine, California, Earthquake, Part I: Wavelet domain inversion theory and resolution analysis", Bull. Seismol. Soc. Am., 92(4): 11921207, 2002.

[2] N. Takahaski, S. Kodaira, T. Tsuru, J.-O. Park, Y. Kaneda, K.Suyehiro, H. Kinoshita, S. Abe, M. Nishino, and R. Hino, "Seismic structure and seismogenesis off Sanriku region, northeastern Japan", Geophys. J. Int., 159,129-145, 2004.

[3] Y. Yamazaki, Z. Kowalik, and K.F. Cheung, 'Depth-integrated, nonhydrostatic model for wave breaking and run-up', Int. J. Numer. Methods Fluids, 61(5), 473-497, 2009 
[4] Y. Yamazaki, K.F. Cheung, and Z. Kowalik, "Depth-integrated, nonhydrostatic model with grid nesting for tsunami generation, propagation, and run-up", Int. J. Numer. Methods Fluids, Doi: 10.1002/fld.2485, in press.

[5] T. Lay, Y. Yamazaki, C. J. Ammon, K.F. Cheung, and H. Kanamori, "The great 2011 Tohoku-oki (Mw 9.0) earthquake: Comparison of deepwater tsunami signals with finite-fault rupture model predictions", Earth, Planets and Space, 63, doi:10.5047/eps.2011.05.030, 2011, in press.

[6] T. Lay., C. J. Ammon, H. Kanamori, L. Xue, and M. J. Kim, "Possible large near-trench slip during the great Tohoku (Mw 9.0) earthquake", Earth Planets Space, doi:10.5047/eps.2011.05.033, 2011, in press.

[7] T.A. Battista, B.M. Costa., and S.M. Anderson, Shallow-Water Benthic Habitats of the Main Eight Hawaiian Islands (DVD). NOAA Technical Memorandum NOS NCCOS 61, Biogeography Branch. Silver Spring, MD, 2007

[8] D. Zhao, Z. Huang, N. Umino, A. Hasegawa, and H. Kanamori "Structural heterogeneity in the megathrust zone and mechanism of the
2011 Tohoku-oki earthquake $\left(\mathrm{M}_{\mathrm{w}}\right.$ 9.0)", Geophys. Res. Lett., 2011, in press

[9] C.J. Ammon, T. Lay, H. Kanamori, and M. Cleveland, "A rupture model of the great 2011 Tohoku earthquake", Earth, Planets and Space, 63, 2011, doi:10.5047/eps.2011.05.015, in press.

[10] Y. Okada, "Surface deformation due to shear and tensile faults in a half space", Bull. Seismol. Soc. Am., 75(4), 1135-1154, 1985.

[11] Y. Yamazaki, and K.F. Cheung, Shelf resonance and impact of nearfield tsunami generated by the 2010 Chile earthquake. Geophys. Res. Lett, 38, L12605, doi:10.1029/2011GL047508, 2011, in press.

[12] S. Munger and K.F. Cheung, Resonamce in Hawaii waters from the 2006 Kuril Islands Tsunami, Geophys. Res. Lett, 35(7), L07605, doi:10.1029/2007GL032843, 2008.

[13] V. Roeber, Y. Yamazaki, and K.F. Cheung, Resonance and impact of the 2009 Samoa tsunami around Tutuila,American Samoa. Geophys. Res. Lett, 37, L21604, doi:10.1029/2010GL044419, 2010. 